\title{
BPR Application
}

\author{
Guoli Yin \\ Technical Development Center, SAIC GM Wuling Automobile Co., Ltd, No.18, Hexi road, 545007, China \\ Tel: 86-0772-375-1096 E-mail: yin.guoli@hotmail.com or guoli.yin@sgmw.com.cn
}

\begin{abstract}
To pursue more success or to be outstanding, many companies apply BPR to breakthrough big issues, to increase efficiency, quality and reduce cost. This paper first introduce what is BPR, the essential of BPR and the benefits of BPR, then, tell us how to implement BPR through a case study. The purpose of his paper is to help readers to have a good understanding of BPR, so as to be able to apply BPR to improve performance of their company.
\end{abstract}

Keywords: BPR, Process, 3 X3 principle, Benefit, BPR implement

\section{Introduction}

Nowadays the requirements of customers vary from person to person. Failure to meet the customer's requirement is likely to drive them into the arms of a competitor. In addition, global competition drives companies to pursue the world's best. On the other hand market conditions change quickly, companies have to move fast to adapt. Hammer and Champy (1993) stated that these three factors force companies to strive for a breakthrough to increase efficiency, quality, reduce cost, to focus on strategy, technology or automation in short time. Business Process Reengineering (BPR) is applied to obtain the above objectives (Chan and Peel, 1998, p45-46). In this article, there is a critical appraisal of BPR, and benefit forthcoming from its implementation. Then, a BPR case study focusing on the process will be undertaken, the purpose of which is to tell how to carry out BPR.

\section{The concept of BPR}

\subsection{The definition of $B P R$}

Researchers and practitioners have defined BPR in different ways with different emphases. Hammer and Champy (1993) defined BPR as "the fundamental rethinking and radical redesign of business processes to achieve dramatic improvements in critical, contemporary measures of performance, such as cost, quality, service and speed." Alter (1990) defined BPR as "a methodical process that uses information technology to radically overhaul business process and thereby attain major business goals". Lowenthal (1994) defined BPR as "the fundamental rethinking and redesign of operating process and organizational structure, focuses on the organization's core competencies, to achieve dramatic improvements in organizational performance" (Mashari, M,A and Zairi, M, 2000,p11). Sethi and King (1998) defined BPR as "a redesign and reorganization of business activities that results from questioning the status quo. It seeks to fulfill specific objectives and can lead to breakthrough improvement. It is often associated with significant cultural and technological changes".

\subsection{Critical appraisal the concept of BPR}

No matter how BPR is defined, its main goal is to redesign business process. Toward this end, IT can be used as an enabler to achieve the goals. Mostly, if the original organization is unfit for the new process, then this would be a main block implementing the new process. So BPR always includes organizational change (Al-Mashari and Zairi, 2000). There are five elements of the above definitions that need to be stressed:

- a focus on business process

- a questioning of the status quo

- specific objectives

- breakthrough achievement

- significant cultural change (Sethi and King, 1998)

Some companies may still confuse BPR with TQM, organizational change and automation due to their similar tools and outcomes. Actually, BPR differs from TQM in two important respects. Firstly, TQM focuses on continuous incremental performance improvement, while BPR focuses on dramatic discontinuous improvement - breaking away from the outdated rules and fundamental assumptions that underlie operations (Bond and Guimaraes, 1996. Choi and Chan, 1997). Secondly, the primary purpose of BPR is to increase effectiveness of accomplishment of the company's management, administrative and operational tasks, while the primary purpose of TQM is to improve the quality (Choi and Chan, 1997). Regarding organizational change, restructuring or 
downsizing has the goal of reducing personnel to improve financial performance and not to reinvent processes. BPR on the other hand aims at reengineering process. This may reduce headcount at the same time but is not main goal. Regarding automation, this is not BPR. It is only used in BPR to obtain efficient processes (Choi and Chan, 1997).

\subsection{Critical appraisal the benefit of the implementation of $B P R$}

To be aware of the benefits of BPR, it is necessary to understand the implementation process of BPR. Suppose that the organization follows $3 \times 3$ process reengineering. An analysis of the implementation shows the kind of benefits that can be brought to the organization from each phase. Figure 1 shows $3 \mathrm{X} 3$ principle of process reengineering. Figure 1 shows three phases, In the initiation phase, important business processes are identified and scrutinised for their potential for improvement. Within this analysis the acquisition process of prototype parts was identified as a crucial process within the development. This will help the organization form process focus thinking in the future work. In the definition phase, the team analyzes the cause and finds the measures through cooperation. It will help to form a teamwork atmosphere in the organization. At this stage, the team reorganizes the structure to adapt the new process, it will help to build a process focus organization. That means the new organization will more flexible and efficient than the former one. The focus on core business processes is one of the main benefits that BPR brings to the organization (Glykas \& Valiris, 1999). If the organization uses information technology (IT) to simplify the complex work to obtain dramatic improvement, then it will help the organization build a powerful network environment with which improve the company's competitiveness. In the control phase, to stabilize success, it is required to educate employees to work under the new systems and procedures for continuous improvement. This helps the organization to obtain:

- Employee awareness for the need of continuous improvement

- Continuous fundamental rethinking

- guarantee that the BPR philosophy will continue to flourish in the organization

- Proper communication, coordination and control established in the organization (Glykas \& Valiris, 1999).

Once BPR is successfully implemented, the organization will reap at lest one of the following benefits:

- Productivity, decreased cycle time, inventory or cost

- Profitability, increased economic growth

- Quality, improved products or services and related information (O’Neill and Sohal,1998).

\section{Case Study of BPR}

In this case, the task is to shorten the order processing process from nine days to one day by reengineering the process. Appendix 1 shows the details of the original process.

\subsection{Analyzing and discussing the existing process}

\subsubsection{Flow diagram of existing process}

Based on the given case study details (Appendix 1), flow diagram of existing process was produced and shown in Figure 2.

\subsubsection{Problems within the existing process}

Peppard and Rowland (1995) concluded that non-value-adding activities should be eliminated, the remain process should be simplified, the simplified tasks should be integrated and basically sound process should be automated when implement BPR( It is also called ESIA method). Based on above theories, the obvious problems in the case which affect the efficiency lie in the following aspects:

a) Involved units work separate. It takes a long time to deliver information from department to department or person to person. The current organization adopts typical functional structure in which each department is responsible for undertaking little part of a large whole. The functional boundaries between departments lead weak co-ordination and inefficiency. For example, sales department use their own file form which need to translate into company terms. The transferring of information is a form of duplication it is non-value-adding activities. Therefore, it is necessary to reorganize the structure.

b) Reformatting the order waste time. The order need to be rewritten when it pass from sales department to marketing department. It is duplication job which need to be eliminated.

c) Credit check requires three to four days by an outside agency. It is a big problem in this case as the goal of order process is now only one day. Another problem is the credit check should happen before the Client 
Group assigns the order number, because the company will not supply the container to customers if they have bad credit. The order processing should be stop at once at the beginning and no need keep continue in the company, because the subsequent job belongs to non-added value process. Here, the process of credit check should be fully refined.

d) In Engineering Department, a simple job was divided into two parts and each part was responsible by different people. The Production Controller has to rework and get relevant information from Supervisor. The rework job is a kind of waste need to be removed and the simple jobs need to be integrated.

e) In the current process, information is delivered by paperwork. It ties up the armies of bureaucrat, yet contributes little to the main job. It could also be eliminated by utilizing IT.

\subsection{BPR Implement}

\subsubsection{Flow diagram of new process}

Now, the output from 3.1.1 and 3.1.2 can be utilized to reengineer the process. The new process is based on reengineering organization structure and utilizing IT. Firstly, in order to eliminate the functional boundaries, original functional organization structure need to be change to matrix structure (Figure 3). A cross-functional team with the team members come from functional department is built. In this case, the members come from sales, and engineering department. Secondly, the method of utilizing IT to cancel paperwork and integrate credit check work is used. IT acts as a powerful tool in this case, when client information is put into IT system, it will automatically match credit record and accomplish electronic credit check immediately. This credit automatic check system will be designed with outside agency in advance. Again, ESIA is applied for reengineering. The new flow diagram can be designed as Figure 4.

\subsubsection{Interpreting of the new process}

The new process can be interpreted: The employee from sales who belong to cross-functional team receives the order via mail, fax or telephone, then, put the client and order information into a certain database in company terms, and client credit check is completed at the same time. If there is no problem with the credit check, the information will keep in "need to deal with" database. And the computer will alarm the next responder who comes from engineering department. All numbers in this cross-functional team can access this database at anytime. If finance wants to get information they can login this database, same as marketing. The employees who come from engineering department get information immediately only when the client was passed the credit check. They estimate the work content immediately based on the information, and reserve the required machines online and then add the due date into the file. When the job of generating due date was finished, the computer system will alarm the person who create the information. The team member from sales get the due date information online immediately, and send a fax to the customer who order the container. The whole order processing process can be completed in one day. IT plays a key role to ensure the success of BPR implementation in this case.

\subsection{How the expected improvement with respect to the reengineering concept}

In this case, the expected improvement is dramatic speed improvement: shorten order processing process from nine days to one day. It is a breakthrough which need use BPR approach to obtain the target. Based on the problem a) which mentioned in 3.1.2, the organization structure is redesigned from functional structure to matrix structure. Based on the problem b) to e), IT is applied to support radically redesign business process and involved major business goals. Furthermore, paperwork and rework will is eliminated: the production group's job is canceled, some job is integrated, such as credit check, the supervisor's job and production controller's job is integrated and assigned to one person. The expected improvement will be got from redesign and reorganization business process that results from questioning the status quo.

\section{Conclusion}

BPR is a tool using critical rethinking, redesign and reorganization, usually supported by IT to optimize the current process. BPR achieves breakthrough outcomes in the areas of customer satisfaction, cost, quality and cycle time. ESIA should be used to guide a systematic approach to BPR. This is concluded by the case study.

\section{References}

Al-Mashari, M. A. and Zairi, M. (2000). Revisiting BPR: a holistic review of practice and development. Business Process Management Journal. 6(1). pp 10-42.

Baumgärtner,A. Walliser,F. and Zinser,S. (1998). Best practice in reengineering: a successful example of the Porsche research and development center. Business Process Management Journal. 4(2). pp 154-167. 
Bond,T. and Guimaraes,W. (1996). Empirically assessing the impact of BPR on manufacturing firms. International Journal of Operations \& Production Management. 1(16). pp 5-28.

Chan,P.S. and Peel,D. (1998). Causes and impact of reengineering. Business Process Management Journal. 4(1). pp. 44-55.

Choi,C.F and Chan,S.L. (1997). Business process re-engineering: evocation, elucidation and exploration. Business Process Management Journal. 3(1). pp 39-63.

Glykas,M. and Valiris,G. (1999). Critical review of existing BPR methodologies. Business Process Management Journal. 5(1). Pp 65-86.

O’Neill,P and Sohal,A.S. (1998). Business process reengineering: application and success - an Australian study. International Journal of Operations \& Production Management. 18(1). pp 832-864.

Peppard, J and Rowland,P. (1995). The essence of business process re-engineering - London: Prentice Hall.

Sethi,V. and King,W.R. (1998). Organizational transformation through business process reengineering: apply the lessons learned. - Upper Saddle River, N.J: Prentice Hall.

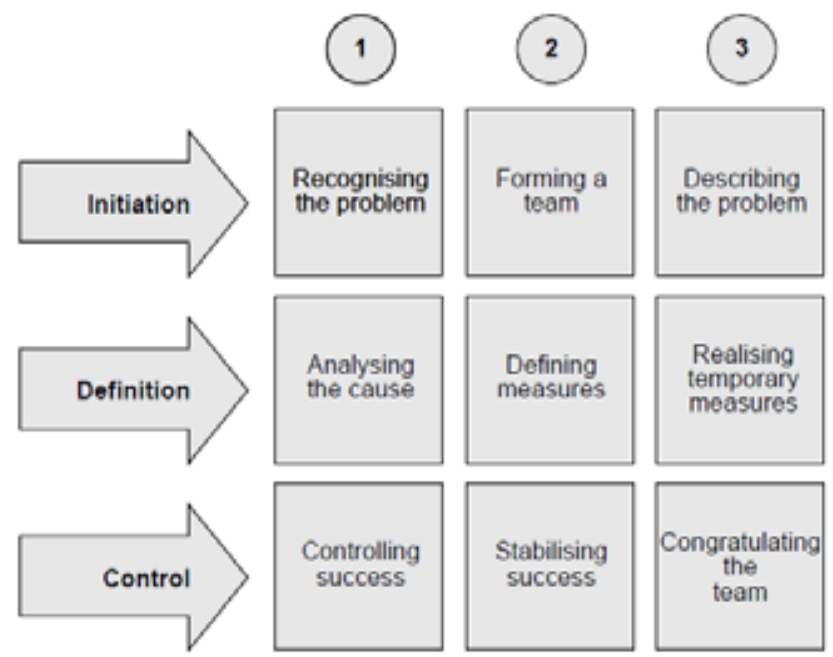

Figure 1. 3X3 Principle of Process Reengineering (Baumgärtner, Walliser \& Zinser, 1998, p157)

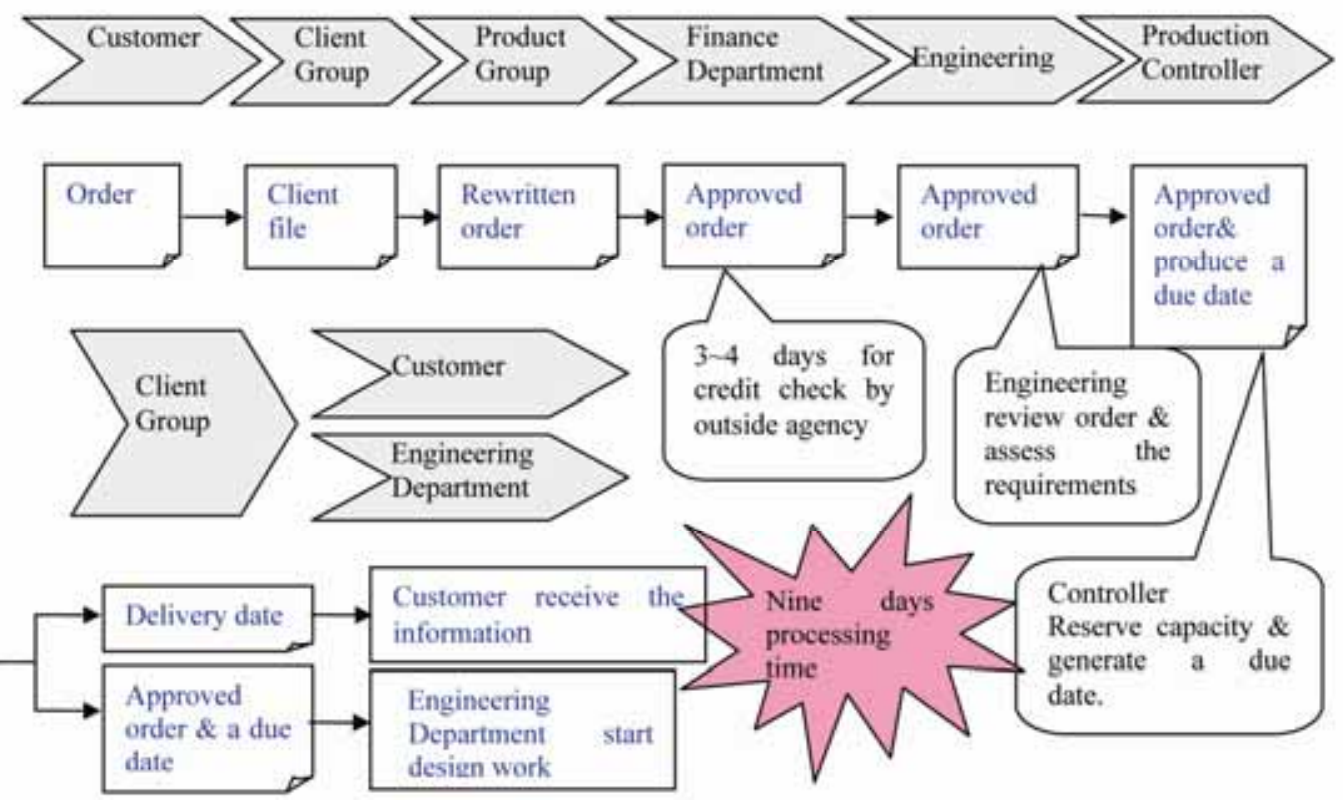

Figure 2. Flow Diagram of Existing Process 


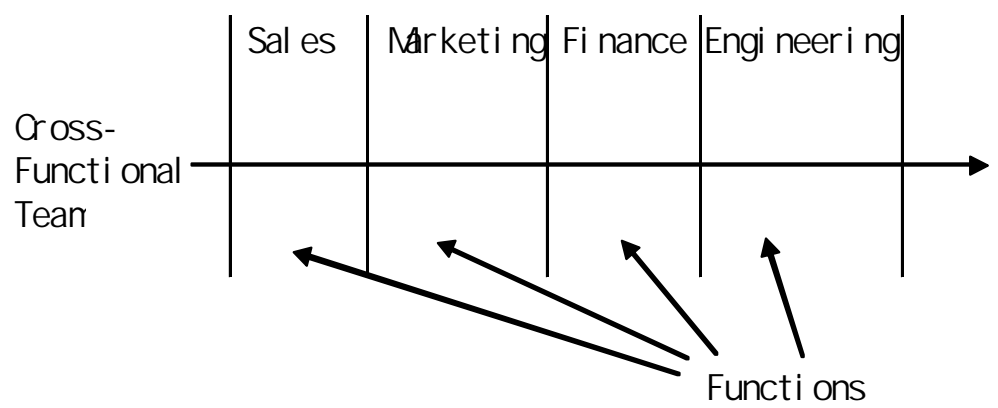

Figure 3. Matrix Organization Structure
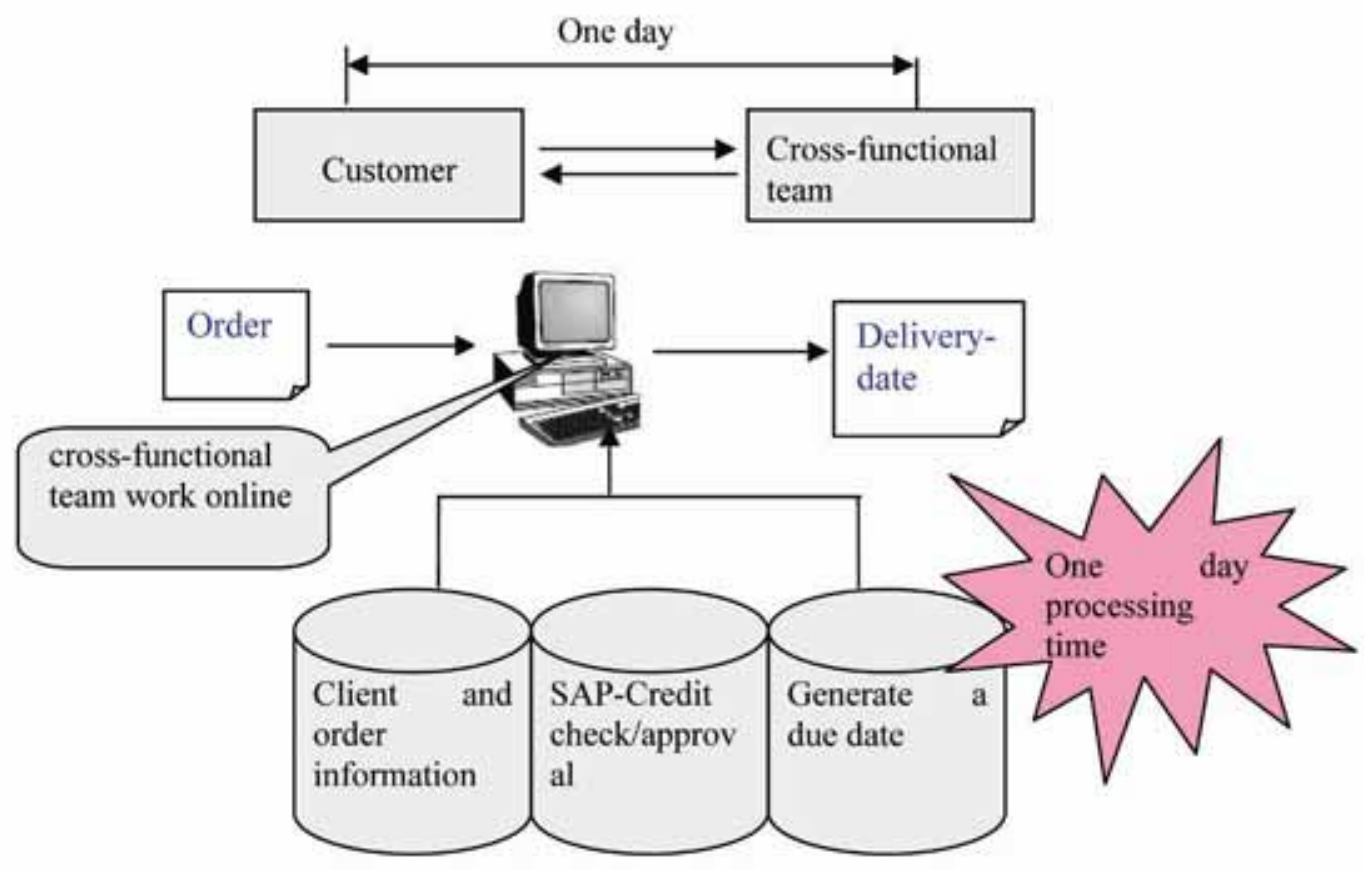

Figure 4. The Flow Diagram of New Process 


\section{APPENDIX 1: CASE STUDY DETAILS}

The company designs and manufactures specialist containers and has sales revenues of $£ 30$ million/year. Each product sold is unique to its end use and therefore every item must be specially engineered. There is, however, significant similarity from one unit to the next. Whilst efforts have been made to reduce the manufacturing lead-time, the activity of getting an order processed and a delivery date sent to the customer has received no attention. However, after an investigation it was found that it was taking nine days to carry out this activity. This was particular problematic as the company is trying to have a lead-time of 3 weeks from receipt of order to despatch. The existing process for order processing is:

The Client Group (reporting to sales) receives the order via mail, fax or telephone. A group member assigns an order number and creates a client file. Added value time $=\mathbf{1 5}$ minutes.

The Product Group (reporting to marketing) receives the file from the Client Group, checks it against the order, and rewrites the order, translating it into company terms. Added value time $=\mathbf{2 0}$ mins.

The rewritten order is forwarded to the Finance department for approval. It requires three to four days for a credit check by an outside agency. Once approved the order is forwarded to Engineering. Added value time $=15$ mins.

In Engineering, a supervisor would review the order, assess what its manufacturing requirements were (machine types and an estimate of the work content). The order was then sent to the Production Controller. Added value time $=\mathbf{4 5}$ mins.

The Production Controller would reserve the required capacity on the relevant machines and would then generate a due date based upon this information. Added value time $=\mathbf{2 0}$ mins. He would forward the file to the Client Group who would send a delivery date to the customer. Added value time $=\mathbf{5}$ mins. A copy of the order was made by the Client Group and forwarded to the Engineering Department so they could begin the relevant design work.

In total, the process took on average nine days. The Company would like a lead-time of 1 day to be achieved for this process as a result of reengineering. 